\title{
Erratum: Patent drop reveals pressure on industry
}

Stacy Lawrence

Nat. Biotechnol. 22, 930-931 (2004)

On page 930, second paragraph, third line, mention was made of "two recent studies published in June by researchers from the Association of University Technology Managers (AUTM) in a joint effort with colleagues from Georgetown and Duke Universities and by law firm Finnegan, Henderson, Farabow, Garrett \& Dunner." It should have read "two recent independent studies published in June, one by researchers from the Association of University Technology Managers (AUTM), Georgetown University and Duke University, and a second by law firm Finnegan,

Henderson, Farabow, Garrett \& Dunner."

\section{Erratum: Cash-strapped biotechs find financing alternative}

Peter Mitchell

Nat. Biotechnol. 22, 1057-1058 (2004)

On page 1057, third paragraph, sixth line, it was stated that Stuart Bressman works for investment bank Brown Raysman Millstein Felder \& Steiner in New York City. It should have read that Bressman works for law firm Brown Raysman Millstein Felder \& Steiner.

\section{Corrigendum: Engineering sweet targets for magic bullets}

\section{Ten Feizi}

Nat. Biotechnol. 22, 1244-1245 (2004)

On Page 1245, col. 2, paragraph 2, last line, "others 3 " should have been "others2".

Corrigendum: The genome sequence of the capnophilic rumen bacterium

\section{Mannheimia succiniciproducens}

Soon Ho Hong, Jin Sik Kim, Sang Yup Lee, Yong Ho In, Sun Shim Choi, Jeong-Keun Rih, Chang Hoon Kim, Haeyoung Jeong, Cheol Goo Hur \& Jae Jong Kim

Nat. Biotechnol. 22, 1275-1281 (2004)

On page 1281, under 'Culture conditions,' $1 \mathrm{~g} \mathrm{NaCl}, 1 \mathrm{~g}\left(\mathrm{NH}_{4}\right)_{2} \mathrm{SO}_{4}$ should be $2 \mathrm{~g} \mathrm{NaCl}, 2 \mathrm{~g}\left(\mathrm{NH}_{4}\right)_{2} \mathrm{SO}_{4}$.

\section{Corrigendum: Advances in the production of human therapeutic proteins in yeasts and filamentous fungi}

\section{Tillman U Gerngross}

Nat. Biotechnol. 22, 1409-1414 (2004)

The figure below replaces Figure 3 on page 1413. The new figures corrects errors in the structures and the key of the old figure.

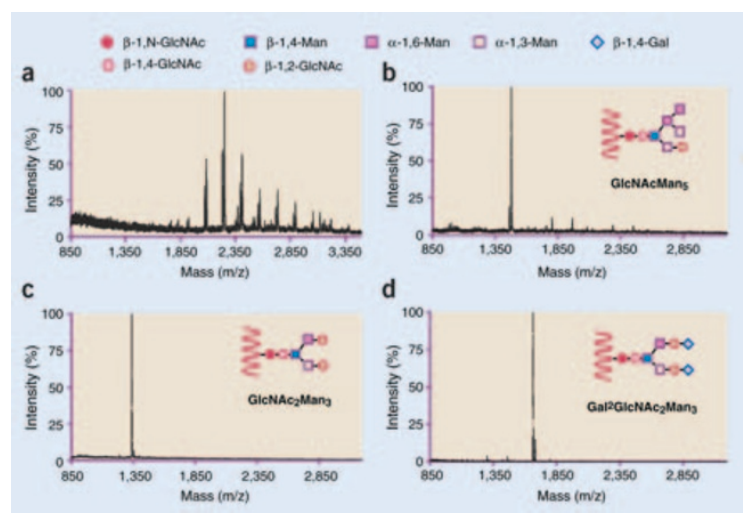

